Alejandro Rodríguez Díaz del Real

\title{
El conquistador conquistado Álvar Núñez Cabeza de Vaca y la conquistada conquistadora Sor Juana Inés de la Cruz. Análisis de dos identidades divergentes a partir de dos breves obras
}

\begin{abstract}
Palabras clave: Leyenda Negra, Cabeza de Vaca, Sor Juana Inés de la Cruz, indigenismo, barroco
\end{abstract}

DOI: 10.4312/ars.11.2.232-244

\section{Introducción}

El tradicional e indiferenciado discurso acusador que impregna de tremendismo acrítico la conquista de América por parte de España se ha visto revisado con la aparición de dos importantes publicaciones en 2016. La primera de la historiadora malagueña María Elvira Roca Barea: Imperiofobia y Leyenda Negra. Roma, Estados Unidos y el Imperio español. Es un ensayo en el que la autora analiza la hispanofobia como un fenómeno en constante crecimiento desde la expulsión de los judíos de España y su consecuente recepción por parte de terceros países, en los que el antisemitismo deriva en hispanofobia. A partir de ahí, y con la presencia española en Italia, se difunde el contraste entre el español bárbaro e inculto frente al refinamiento italiano. Con la posterior conquista de América y las exageraciones de Las Casas, la casa de Orange instrumentó a este autor propagandísticamente en los Países Bajos, impulsando la traducción y edición de la Brevísima relación de la destrucción de las Indias (en ediciones dotadas de las truculentas ilustraciones de Theodor de Bry) con el objeto político de desprestigiar a España. Se beneficiaba así el incipiente nacionalismo neerlandés, precisamente el nacionalismo que más partido político sacó a la Reforma. El descubrimiento y la conquista de América se convierten desde muy pronto en talón de Aquiles del prestigio internacional de la Monarquía hispánica, desprestigio que es astutamente utilizado en las luchas de poder en los Países Bajos, una guerra civil que será presentada de forma indiferenciada, distorsionada, maniquea e interesada como simple e inevitable enfrentamiento entre holandeses (que se liberan de la tiranía) y españoles (que oprimen y tiranizan) ${ }^{1}$.

1 Señala Roca Barea $(2016,237)$ que «en 1573 hay en Flandes 54300 soldados al mando del duque de Alba. De ellos solo 7900 son españoles. Del resto, como mucho, el número mayor, unos 30000, eran 
La segunda publicación se titula La sombra de la leyenda negra, obra colectiva de quince autores dirigida por María José Villaverde Rico y Francisco Castilla Urbano. Los temas abarcan desde la propia contribución española a la construcción de la leyenda negra (Las Casas, los arbitristas, etc.) hasta el retorno de las tesis negrolegendarias durante el siglo XIX con la irrupción del liberalismo, pasando por las polémicas ilustradas al respecto, los jesuitas, la ciencia española, las independencias de las nuevas naciones latinoamericanas, etc. La envergadura de tan ambiciosa obra invita a pensar que la leyenda negra ha dejado de ser un tema relativamente latente o durmiente, desde que Julián Juderías publicara en 1914 su famoso y polémico libro La leyenda negra y la verdad histórica: contribución al estudio del concepto de España en Europa, de las causas de este concepto y de la tolerancia religiosa y política en los países civilizados ${ }^{2}$.

A partir de contexto de partida, en este artículo nos proponemos contrastar a dos autores cuya obra y trayectoria vital disienten del discurso de opresión que impregna dicha leyenda en sus rasgos generales más estereotipados. Por un lado el breve relato de la asombrosa aventura de Álvar Nuñez Cabeza de Vaca, Naufragios, como muestra de que no todo fue crueldad e insensibilidad entre los conquistadores, hasta el punto de acabar su protagonista fascinado o "conquistado» por aquello que se disponía a conquistar; por otro, salvando un considerable lapso de más de un siglo, Neptuno alegórico, de Sor Juana Inés de la Cruz, otra obra también breve consistente en la descripción de un arco triunfal de bienvenida a los nuevos virreyes de Nueva España. En el primer caso tendríamos un fenómeno de viaje, transposición o vector desde la cultura occidental a la indígena, en el segundo caso un vector opuesto que, alejándose de un contexto cultural criollo - no tanto mestizo- incurre en el más ortodoxo de los eurocentrismos: el de la obsesión por los autores grecolatinos y las alegorías mitológicas con objeto de revisar y reubicar la realidad mexicana, insertándola en ese canon iconográfico e ideológico occidental. Por ello podríamos hablar de su autora como una "conquistada conquistadora» o americana europeizada. La camaleónica aventura de Cabeza de Vaca, por su parte, contrasta con la de la poeta Sor Juana Inés de la Cruz, docta religiosa que interioriza el Barroco más exacerbado, y que tiene como ilustrativa muestra el Neptuno alegórico, curiosa descripción de los lienzos que decoraron el fastuoso arco triunfal construido, como decíamos, para darles la bienvenida a los nuevos virreyes de México el 30 de noviembre de 1680.

flamencos. El ejército de Alejandro Farnesio en 1581 se componía de unos 60000 hombres. De ellos solo 6300 eran españoles. Los italianos eran 5000. El resto, esto es, la mayoría, eran holandeses: unos 48000».

2 El término leyenda negra fue empleado por primera vez por Emilia Pardo Bazán, en una conferencia que ofreció el 18 de abril de 1899 en la Sociedad de Conferencias de París, con el título «La España de ayer y la de hoy. (La muerte de una leyenda)». Disponible en la red: http://www.filosofia.org/ aut/001/1899epb4.htm [20. 6. 2017]. 
Estamos ante dos obras radicalmente diferentes: el de un proceso asombroso de adaptación al medio, si bien el protagonista mantiene una ambigüedad identitaria entre el cristianismo y su paulatino «indigenismo», frente a un camaleonismo opuesto que parte de un marco en el que el elemento americano aún pervive, pero que en cierto modo Sor Juana pasa por alto u olvida, convirtiéndose además en una de las plumas más representativas del estilo y los temas que decide adoptar.

\section{Los Naufragios de Cabeza de Vaca como antiepopeya del conquistador}

En el contexto de la primera confrontación con el otro, de los célebres sermones de Antonio de Montesinos en la Navidad de 1511, de las Leyes de Burgos (1512) ${ }^{3}$, del proyecto de civilización mestiza de Hernán Cortés ${ }^{4}$ (enturbiado por sucesos como la matanza de Pedro de Alvarado en junio de 1520), en el marco también de innumerables violaciones individuales a la dignidad de los pueblos indígenas, de enfermedades que iban por delante de sus propagadores ${ }^{5}$, y de abusos no exclusivamente asignables a ninguna guerra de conquista concreta sino a cualquiera, abusos que llevaron a la promulgación por parte de Carlos V de las Leyes Nuevas en $1542^{6}$, el debate sobre los derechos humanos - del que posteriormente la Francia ilustrada se apropia ${ }^{7}$ que precedió dicha promulgación, (con Francisco de Vitoria, la Escuela de Salamanca y la Junta de Valladolid como epicentros clave de dicho debate $)^{8}$, en ese turbulento pero

3 La Junta de Burgos fue convocada por Fernando el Católico como respuesta a los sermones del 21 y 28 de diciembre de 1511 y en las leyes resultantes se establecieron los principios de la libertad del indio, el compromiso evangelizador de los Reyes Católicos y la Corona de Castilla, la obligatoriedad del trabajo del indio siempre que las condiciones y el salario fueran justos, así como la justificación de la guerra de conquista si los indios se negaban a ser cristianizados, para lo cual se creó la nueva y con el tiempo polémica institución del requerimiento.

4 El mexicanista francés Christian Duverger contribuyó a acabar con la imagen unidimensional que reduce a Cortés a mero conquistador cruel publicando en 2005 la obra Hernán Cortés. Más allá de la leyenda.

5 Cinco años en el caso del Perú. Villaverde Rico, M. J.; Castilla Urbano, F. (2016, 45).

6 Las Leyes Nuevas, cuyo título exacto es Leyes y ordenanzas nuevamente hechas por su Majestad para la gobernación de las Indias y buen tratamiento y conservación de los Indios, pretendieron mejorar las condiciones de vida de los indígenas americanos, con medidas como la reforma de la encomienda.

7 Roca Barea, M. E. (2016, 351-363).

8 Castilla Urbano (2016, 52-53) escribe lo siguiente: «La proclamación del principio de que todos los hombres tienen iguales derechos y de que todos los pueblos gozan de la misma dignidad sí que es un hecho único en la historia, que merece elogios. El debate público y hasta auspiciado por la Corona para averiguar cuál era el trato justo que se debía dar a los indígenas situó a España por encima de los restantes países colonialistas. Ciertamente ningún país engendró a un Las Casas, un Vitoria o una Escuela de Salamanca. De ahí que tenga razón Joseph Pérez en reclamar el reconocimiento debido a España porque sus intelectuales fueron los primeros en combatir la tesis de que un pueblo puede imponer a otro su tutela, con el pretexto de evangelizarlo o civilizarlo. Y también está en lo cierto Molina en afirmar que es una gran ironía que tal actitud autocrítica fuera utilizada políticamente por los rivales de España, para dar origen a la leyenda negra». 
también crucial y necesario proceso de duda, meditación y autocrítica que generó la primera fase de la conquista, se enmarca la expedición de Álvar Núñez Cabeza de Vaca, que quizás ilustre mejor que ninguna otra expedición ese afán de dejarse impregnar por lo nuevo, algo difícil de encontrar en otros europeos de la época.

Álvar Núñez Cabeza de Vaca, tan imbuido de la cotidianidad indígena en su extenso periplo norteamericano de seis años de duración, desde su embarrancamiento en Tampa (1527) hasta su rescate en el norte de México (1536) acaba sorprendiendo a sus rescatadores del Noroeste de Nueva España por su completa adopción de los usos y modos indígenas de vida.

Juan Francisco Maura califica a Cabeza de Vaca como «nuevo mesías», si bien algo falso teniendo en cuenta sus intenciones posteriores:

Se considera a sí mismo y a su expedición, capaz de sobrevivir a todo lo imaginable, emulando incluso al mismo Jesucristo: curaban a los enfermos [...]; iban desnudos y descalzos, lo normal después de un naufragio y nueve años de "peregrinaje»; no tenían codicia, punto este bastante dudoso, ya que lo primero que hace Álvar Núñez nada más llegar a la Corte es pedir el privilegio de ir de Adelantado a la Florida. [...] Quizá el mejor ejemplo en el que pueda evidenciarse su comparación con la figura de Cristo sea el que aparece en el capítulo XXII. En este episodio Álvar Núñez relata [...] cómo resucita a un muerto. Las propiedades milagrosas de este buen hidalgo son francamente alucinantes. (Maura, 2000, 43-44).

Efectivamente, en el capítulo XXII se narra la resurrección de un muerto cuyo cuerpo había sido velado por numerosas personas. Álvar Núñez le quita la estera con la que estaba cubierto y consigue resucitarlo, haciendo que todos se alegren al día siguiente. Maura contrasta las palabras del evangelio de Lucas 7, 16-17 («Con esto quedaron todos penetrados de un santo temor, y glorificaron a Dios diciendo: Un gran profeta ha aparecido entre nosotros, y Dios ha visitado a su pueblo. Y esparcióse la fama de este milagro por toda Judea») y las palabras de Álvar Núñez en el capítulo XXII: «Esto causó muy gran admiración y espanto, y en toda la tierra no se hablaba en otra cosa. Todos aquellos a quien esta fama llegaba nos venían a buscar para que los curásemos y santiguásemos sus hijos» (Cabeza de Vaca, 2000, 158). Para Maura lo que hizo Álvar Núñez fue crear un «Evangelio del Nuevo Mundo» donde él como protagonista tendría tantos atributos como los que pudiera tener el mismísimo Jesucristo. Sin embargo, Jesucristo no escribió su propia obra y Álvar Núñez sí (Maura, 2000, 45).

Dicho elemento bíblico o de Evangelio del Nuevo Mundo encuentra en un episodio concreto, el vigésimo primero, la evidencia intertextual más clara: «Como 
por toda esta tierra no hay caminos [...] aquella noche me perdí, y plugo a Dios que hallé un árbol ardiendo, y al fuego de él pasé aquel frío aquella noche» (Cabeza de Vaca, 2000, 154).

Necesita Cabeza de Vaca, ante el proceso de aculturación del que será protagonista justo después, si partimos de su relato, un punto de partida cristiano, o mejor aún, cristológico, quizás para blindarse de cara a posibles acusaciones de desviación religiosa tras los numerosos años que pasa inmerso en extrañas tribus de gentiles, es decir, paganos o infieles, convivencia que en aquel contexto histórico indudablemente generaría sospechas en su Castilla natal.

La irrupción de lo salvaje y su inherente brutalidad se produce de inmediato, solo un capítulo después, con la descripción de Mala cosa, un oscuro personaje del que ni los indígenas norteamericanos conocen muy bien su naturaleza, pues lo describe Cabeza de Vaca proveyéndolo de un aura de inquietante monstruosidad que recuerda, con una anticipación de siglos, a los relatos góticos y del romanticismo negro:

Estos y los de más atrás nos contaron una cosa muy extraña, y por la cuenta que nos figuraron parecía que había quince o diez y seis años que había acontecido, que decían que por aquella tierra anduvo un hombre, que ellos llaman Mala Cosa, y que era pequeño de cuerpo, y que tenía barbas, aunque nunca claramente le pudieron ver el rostro, y que cuando venía a la casa donde estaban se les levantaban los cabellos y temblaban, y luego parecía a la puerta de la casa un tizón ardiendo. Luego, aquel hombre entraba y tomaba al que quería de ellos, y dábales tres cuchilladas grandes por las ijadas con un pedernal muy agudo, tan ancho como una mano y dos palmos en luengo, y metía las manos por aquellas cuchilladas y sacábales las tripas (Cabeza de Vaca, 2000, 159).

Análogamente exótica y fascinante por su valor antropológico de observación es la descripción de lo que él denomina «diablura homosexual» entre dos indígenas. Cabeza de Vaca documenta la existencia de una pareja de hombres que viven juntos, lo cual constituye para un observador del s. XVI una (mínima) reflexión sobre la tolerancia hacia heterodoxias sexuales en la sociedad indígena, además de suponer una mención arriesgada si no hubiera sido por la previa profesión de fe cristológica que mencionábamos más arriba con el árbol ardiente y su relación con la zarza bíblica: «En el tiempo que así estaba, entre estos vi una diablura, y es que vi un hombre casado con otro» (Cabeza de Vaca, 2000, 173). Es tanto más irritante que tras estos — para él— chocantes encuentros, aparezca una defensa tan apasionada de los indios:

Mas como Dios nuestro Señor fue servido de traernos hasta ellos, comenzáronnos a temer y acatar como los pasados y aun algo más, de que no 
quedamos poco maravillados; por donde claramente se ve que estas gentes todas, para ser atraídas a ser cristianos y a obediencia de la imperial majestad, han de ser llevados con buen tratamiento, y que éste es camino muy cierto, y otro no (Cabeza de Vaca, 2000, 199).

Juan Francisco Maura apunta a pie de página que «Cabeza de Vaca y los suyos se presentan como los «defensores» de los derechos de los indios frente a las crueldades de los españoles» y que «ensalza las virtudes cristianas para llevar a los indios por el buen camino» (Maura, 2000, 199).

Llama la atención la parquedad de atuendos a la que Cabeza de Vaca acostumbra al lector desde el capítulo XVI: «Fueron seis años el tiempo que yo estuve en esa tierra solo entre ellos y desnudo, como todos andaban» (Cabeza de Vaca, 2000, 134), a pesar de que constantemente, tal como puede desprenderse de la lectura del capítulo XXIX, recibe mantas como regalo de los indígenas con los que se cruza: «y dieron muchas cuentas, y muchas mantas de vaca» Cabeza de Vaca (2000, 182, 190-191, 193, 199). Estos regalos estaban relacionados con el hecho de que Cabeza de Vaca se presenta como curandero e incluso médico que practica operaciones quirúrgicas de diversa índole a los indígenas que lo precisan:

Aquí me trajeron un hombre, y me dijeron que había mucho tiempo que le habían herido con una flecha por el espalda derecha, y tenía la punta de la flecha sobre el corazón. Decía que le daba mucha pena, y que por aquella causa siempre estaba enfermo. Yo lo toqué, y sentí la punta de la flecha, y vi que la tenía atravesada en la ternilla, y con un cuchillo que tenía le abrí el pecho hasta aquel lugar, y vi que tenía la punta atravesada, y estaba muy mala de sacar. Torné a cortar más, y metí la punta del cuchillo, y con gran trabajo en fin la saqué. Era muy larga, y con un hueso de venado, usando de mi oficio de medicina, le di dos puntos (Cabeza de Vaca, 2000, 182-183).

Es esta la razón por la que la gratitud de la población indígena hacia el extranjero que se desnuda como ellos va extendiéndose y cobrando una magnitud inesperada:

[...] y cuando hube sacado la punta, pidiéronmela, y yo se la di, y el pueblo todo vino a verla, y la enviaron por la tierra adentro, para que la viesen los que allá estaban, y por esto hicieron muchos bailes y fiestas, como ellos suelen hacer. [...] Esta cura nos dio entre ellos tanto crédito por toda la tierra, cuanto ellos podían y sabían estimar y encarecer (Cabeza de Vaca, 2000, 183).

El líder espiritual en que se convierte Cabeza de Vaca llega a hablar de un número exagerado de seguidores: "Muchas veces traíamos con nosotros tres o cuatro mil personas» (Cabeza de Vaca, 2000, 185) y los indígenas llegan al extremo de idolatrarle hasta el punto de no atreverse ni a beber ni a comer sin su permiso. Por cualquier lugar 
por el que pasa, el explorador es agasajado con toda clase de ofrendas. No escatima el autor todo tipo de descripciones y excursos de carácter etnográfico, que intercala de forma casi impresionista en el breve relato de su periplo que constituye Naufragios. Ese interés antropológico resulta llamativo para cualquier lector atento que reflexione sobre la «literatura de viajes», si la hubiera, o mejor dicho si no sonara a anacrónica etiqueta, o bien la literatura, más cercana e influyente, de crónicas o libros de a bordo del siglo XV y XVI.

Merece mención, además, también por su aparente anacronicidad y refrescante igualitarismo, una curiosa observación sobre el trato positivo que reciben las mujeres indígenas: «Entre estos vimos las mujeres más honestamente tratadas que a ninguna parte de Indias que hubiésemos visto» (Cabeza de Vaca, 2000, 194), algunas de las cuales le traían sus recién nacidos para que los bendijese.

Tras atravesar territorios inmensos en los que se habla todo tipo de lenguas, a pesar de cuya variedad Cabeza de Vaca afirma que no son obstáculo para la concordia y el entendimiento, aunque frecuentemente fuera mediante señas, se produce, ya en el capítulo XXXII, el momento crucial de la narración en relación con el tema que nos ocupa, y que consiste en la defensa de los derechos de los indios frente a los cristianos españoles (nota 14).

\section{El Neptuno alegórico de Sor Juana Inés de la Cruz: el apasionado eurocentrismo de una intelectual criolla}

Como antítesis de la adopción de lo tribal americano como propio en los Naufragios de Cabeza de Vaca proponemos un curioso ejemplo de un subgénero literario peculiar y muy cultivado en su contexto histórico: el de la descripción de los lienzos o imágenes emblemáticas ${ }^{9}$ que decoraron el arco triunfal con el que se recibió a los nuevos virreyes de Nueva España en México, el 30 de noviembre de 1680, que corrió a cargo de la religiosa Sor Juana Inés de la Cruz, la intelectual más destacada del barroco novohispano.

9 El género de la emblemática, que ejerce una influencia clave en esta obra de Sor Juana, nace con Andrea Alciato a principios del siglo XVI. Su Libro de los emblemas, publicado en 1531, bebe a su vez en gran medida del Sueño de Polífilo (Hypnerotomachia Poliphili) de Francesco Colonna, novela alegórica -con un conjunto de «visiones» medievales bajo el signo del amor entendido como lucha, en palabras de Pilar Pedraza- publicada en 1499 por la prestigiosa editorial de Aldo Manuzio en Venecia. En relación con Alciato, Mino Gabriele comenta que sus versos persiguen estimular la creatividad de los pintores, orfebres, etc., para producir enseñas, imagines, signa, pudiéndose interpretar como una invitación a renovar en ciertos ámbitos artísticos ese lenguaje alusivo y «jeroglífico» que es la base de la misma emblemática, de la que el ancla aldina representa ejemplarmente la formulación gráfica: esencial y simbólica. [...] icones symbolicae, motivos y figuras de fuerte impacto alegórico. Baste pensar en la misma medallística renacentista, en la tradición de las antiguas gemas con incisiones o a la numismática romana. (Gabriele, M., Introducción a Il libro degli Emblemi, Milano, 2009). En España, el autor que más parece influenciar en el Neptuno alegórico de Sor Juana es Saavedra Fajardo y su Idea de un príncipe cristiano (1640). 
Inspirados en los arcos conmemorativos romanos, estas construcciones eran independientes y constaban, tal y como describe Vincent Martin, de cuatro lados y tres arcos. Cada fachada llevaba un tablero principal; la del norte, el retrato de los nuevos virreyes; y la del sur, insignias y hechos relacionados con los príncipes aztecas (Martin, 2009, 27).

Hay que comenzar destacando la enorme relevancia de un género a primera vista secundario, el de la emblemática, muy extendido en la Europa renacentista y barroca desde que Alciato publicara sus Emblemas en 1531. Aunque sería más adecuado hablar de subgénero de la emblemática específica de arcos triunfales, efímeras construcciones difíciles de disociar de un gusto estético peculiar y muy popularizado en dicha época. Vincent Martin nos proporciona una descripción que nos permite imaginar el resultado: los lemas de los ocho lienzos que componían la parte superior de dicho arco, más seis jeroglíficos situados en las basas estaban pintados cada uno en un listón, y dotados de un epigrama en un tarjón o escudón al pie del cuadro. El arco se asemejaba a un enorme libro de emblemas a la intemperie con todas sus páginas abiertas al mismo tiempo (Martin, 2009, 21).

Estas estructuras siguieron siendo del gusto mexicano casi medio siglo después de que en España pasaran de moda, a pesar de las crecientes dificultades económicas. Según Martin,

México, en cambio, seguía sintiendo la necesidad de impresionar, de ufanarse de ser la Roma o la Venecia del «Nuevo Mundo». A la llegada de los nuevos mandatarios, tras un largo y peligroso viaje, había que asombrarlos con todo, incluyendo el brillo de la ciudad y de los creadores de alegorías. Así como en la Eneida Virgilio cuenta el establecimiento de Roma, en el Neptuno, inspirada o guiada por el gran poeta clásico, alegoriza Sor Juana a México, creándole ecos romanos. Se refiere también a otras ciudades: a Venecia (por los canales), a Delos (por las sacerdotisas y sibilas), a Atenas (por Atenea/Minerva), a Mantua (por Alciato y por los antepasados de la virreina María Luisa). En su espectáculo Sor Juana ayuda a crear una especie de auto sacramental grecoromano de la vida ciudadana imaginaria de la que formaron parte todos los habitantes (Martin, 2009, 28).

La devoción por la cultura de Grecia y Roma cruza, pues, el Océano, y pasa a convertirse en motivo de ferviente imitación para ocasiones festivas. Esta adopción de pautas literarias es previsible en la minoría dominante, es decir, la española, por lo que sorprende esta obra de Sor Juana, quien emula en temática y estilo las corrientes más canonizadas del barroco europeo. Para Vincent Martin el hecho de que se trate de una mujer parece ser más importante que su condición de criolla: «Sor Juana es, hasta 
donde sabemos, la única mujer en la historia de Occidente a quien se le contratara para la invención y el diseño literario de un arco triunfal» (Martin, 2009, 11). Sin quitarle trascendencia a dicha circunstancia en una autora tan indudablemente protofeminista, creemos que es al menos igualmente relevante su origen social, pues demuestra de manera incontestable la movilidad y posibilidad de ascenso social y cultural de una comunidad tendencialmente discriminada, al menos si atendemos al discurso negrolegendario. Y es más significativo aún que su obra no consista tanto en el tratamiento de temas y elementos lingüísticos indígenas, como podría ser el caso del Inca Garcilaso (en los temas) o de José María de Arguedas, ya en el siglo XX (en el peculiarísimo crisol lingüístico que se evidencia por ejemplo en Los ríos profundos), como en el hecho de que Sor Juana, en su Neptuno, calque en contenidos y estilo la escritura que impera en una metrópoli a muchos miles de kilómetros de distancia, alejándose tanto del mundo náhuatl que tan familiar le es y por el que siente, como es sabido, tan empática cercanía.

Baste el simple dato numérico de que, en un opúsculo breve como el que nos ocupa, Sor Juana despliega todo un arsenal de más de doscientas citas en latín. Para García Valdés, la obra es una de las más eruditas de la escritora, quien continuamente utiliza referencias y alusiones a Homero, Teognis de Mégara, Platón, Eurípides, Sócrates, Ovidio, Cicerón, Virgilio o Plutarco (García Valdés, 2010, 24).

Tomamos como ejemplo ilustrativo el «Argumento del segundo lienzo», en el que la autora une de manera conceptista mitología e ingeniería hidráulica, la que precisa la ciudad de México para evitar las constantes inundaciones que la asolaban: «Al diestro lado [...] se descubría una ciudad ocupada de las saladas iras del mar: copia de la que en Grecia [...] anegaron sus furiosas olas» (De la Cruz, 2009, 125).

Vincent Martin apunta que la ciudad griega a la que hace alusión Sor Juana es Argos y relaciona su mención con la construcción allí de un templo a Neptuno, Neptuno Prosclistio $^{10}$. Siguiendo la fuente renacentista que Sor Juana más cita, las Mythologiae de Natal (Natale Conti), Martin explica oportunamente que en el apartado que el mitógrafo italiano dedica a Neptuno/Poseidón en la tierra de los naturales de Argos (argivos) debía quedar bajo la advocación de Juno/Hera y en el momento en que esto fue anunciado (por Ínaco), una gran parte del campo fue inundada y sumergida. Tras suplicar Juno/Hera a Neptuno/Poseidón que desviara el mar, en ese lugar los argivos erigieron un santuario precisamente a Neptuno Prosclistio (Conti, 1988, 151; Martin, $2009,125)^{11}$.

10 Proklystios: «el que inunda».

11 El epíteto añadido a Neptuno procede de Pausanias, Descripción de Grecia, 2, 22, 4. 
Continúa pues Sor Juana con la descripción de su segundo lienzo:

A su lado estaba Neptuno a quien, afectuosa, pedía socorro para la ciudad de Ínaco, su alumno, dada ya a saco a los marinos monstruos, y el piadoso dios, no queriendo emplear generosas iras en los indefensos griegos [...] apartaba con el poderoso tridente las aguas que, obedientes, se volvían a encarcelar con las llaves de arena que les impuso su Eterno Autor. Representaba esta inundación la que es continua amenaza de esta Imperial Ciudad, preservada de tan fatal desdicha por el cuidado y vigilancia de los señores virreyes, y nunca más asegurada que cuando no sólo tiene propicio juez pero espera tutelar numen en el excelentísimo marqués de la Laguna, que si allá (como refiere Natal, tomándolo de Heródoto) formó Neptuno una laguna en que fluyesen las copiosas aguas del Peneo [cita en latín a Conti] nosotros esperamos mejor Neptuno que, contraponiendo la hazaña, forme un río por donde fluya una laguna en su tan necesario como ingenioso desagüe (De la Cruz, 2009, 126).

Sorprendiéndonos distraídos entre emblemática y mitología, se adentra además en este pasaje nuestra autora en un campo muy concreto y peculiar de la literatura barroca, tan interdisciplinar como el simbolismo del propio arco triunfal, y que es el de la ingeniería de grandes (y a menudo delirantes) proyectos de los arbitristas.

Además, se da la circunstancia de que el nuevo virrey ostenta el título de Marqués de la Laguna, un título nobiliario ${ }^{12}$ creado diez décadas antes en lo que actualmente es La Rioja, que evoca la laguna sobre la que se asienta la Ciudad de México, coincidencia que no quiso desaprovechar Sor Juana para desplegar todo su potencial conceptista.

En la más auténtica tradición del concepto quevediano (la influencia de Quevedo, fallecido pocos años antes del nacimiento de Sor Juana Inés, es evidente) Sor Juana une, como decíamos, no solo mitología con la necesidad de una obra importante que solucionara el problema de las inundaciones, sino también capta la atención de los nuevos virreyes a través del nexo de la laguna y el templo, que alude tanto al templo a Neptuno en Argos como la (aún incompleta) iglesia catedral de Ciudad de México.

\section{Conclusión}

Teniendo en cuenta las diferencias de contenido, género literario, época e incluso el hecho de que nos encontramos ante un autor y una autora, a la que además se la considera protofeminista, cabe preguntarse cuál es el nexo o vínculo que los relaciona. Nuestra hipótesis es que la conquista de América produjo no solo la imposición de un canon cultural, el europeo, a expensas de la destrucción de los elementos culturales

12 Marquesado de la Laguna de Camero Viejo, en su nombre completo. 
prehispánicos, sino que también hubo un proceso de intercambio bidireccional, visible en la peripecia e inmersión indigenista de Cabeza de Vaca por un lado y en la inmensa erudición grecolatina de Sor Juana. A su manera, ambos autores, ambas obras, constituyen una muestra evidente de puente entre dos cosmovisiones que la leyenda negra frecuentemente presenta como irreconciliables. Hay mestizaje ya con la transformación de un jerezano, el protagonista de los Naufragios, oficialmente "descubridor de la Florida», al hacer después algo más trascendental aún que de portar dicho título a los anales de la historia, y es aceptar lo nuevo, adaptarlo e incorporarlo a su propia identidad. Algo parecido a lo que intentó Cortés veinte años antes con su truncado proyecto de civilización mestiza en México, aunque de forma más peregrina o, si se quiere, peripatética, arrastrando a un creciente ejército de acólitos indígenas que terminan por considerarle un jefe espiritual o religioso.

\section{Bibliografía}

Alciato, A., Il libro degli Emblemi. Secondo le edizioni del 1531 e del 1534, Milano 2009. Arguedas, J. M., Los ríos profundos (ed. González Vigil, R.), Madrid 2005.

Cabeza de Vaca, A. N., Naufragios, Madrid 2000.

Colonna, F., Sueño de Polífilo (ed. Pedraza, P.), Barcelona 2008.

Conti, N., Mitologías (ed. y trad. de Consuelo Álvarez, Ma y Iglesias, R. Ma), Murcia 1988, http://interclassica.um.es/investigacion/monografias/natale_conti_mitologia/ (ver)/1 [31. 8. 2017].

De la Cruz, Sor J. I., Neptuno alegórico (ed. Martin, V. y Arenal, E.), Madrid 2009.

Duverger, C., Hernán Cortés. Más allá de la leyenda, Madrid 2013.

García Valdés, C. C., Introducción a su ed. de Los empeños de una casa / Amor es más laberinto, Madrid 2010.

Martin, V., Introducción a Neptuno alegórico, en: De la Cruz, Sor J. I., Neptuno alegórico, Madrid 2009, pp. 11-50.

Maura, J. F., Introducción a Naufragios, en: Cabeza de Vaca, A. N., Naufragios, Madrid 2000, pp. 9-62.

Roca Barea, M. E., Imperiofobia y Leyenda Negra. Roma, Rusia, Estados Unidos y el Imperio español, Madrid 2016.

Villaverde Rico, M. J., Castilla Urbano, F., La sombra de la leyenda negra, Madrid 2016. 


\section{Alejandro Rodríguez Díaz del Real}

\section{Osvojen osvajalec Álvar Núñez Cabeza de Vaca in osvojena osvajalka Sor Juana Inés de la Cruz. Analiza dveh različnih identitet na podlagi dveh kratkih del}

Ključne besede: črna legenda, Cabeza de Vaca, Sor Juana Inés de la Cruz, indigenizem, barok

$\mathrm{Na}$ podlagi dveh nedavnih publikacij, ki sta kritični do tradicionalnega in fatalističnega obravnavanja "Leyende negre« (črne Legende o zgodovinski vlogi Španije) in ki želita osvetliti pozitivne vidike osvajanja Amerike, članek primerja deli, ki prikazujeta odprtost do raznolikosti. Alvar Núñez Cabeza de Vaca v delu "Brodolomi« (Naufragios) le pol stoletja po odkritju Amerike opisuje prepoznanje sebe kot osvajalca, ki pa ga hkrati očara in osvaja ta drugačen in skrivnosten svet, ki mu neprestano vzbuja radovednost. Delo je nastalo v obdobju novih zakonov Karla V., ki odražajo Las Casasov kritični duh in zagovarjanje pravic Indijancev s pretiranim opisom grozodejstev, kar kasneje botruje razvoju tako imenovane protišpanske črne Legende. Članek primerja doživljanje sočutja in spoznavanja drugačnega z izvirnim delom Sor Juane Ines de la Cruz, "Alegorični Neptun« (Neptuno alegórico, 1680), v katerem je prav tako prisotno potovanje, čeprav je bolj literarno kot avtobiografsko, in sicer od ameriškosti do drugačnosti baroka oziroma »evropskosti«. Kljub dolgemu časovnemu intervalu med obema analiziranima deloma, ki se tudi žanrsko razlikujeta, študija pri obeh zazna sprejemanje različnih kultur in neznanih estetskih smernic temu bi danes rekli »opustitev cone udobja« -, s čimer se bogati tako avtorjevo lastno doživetje in ustvarjalnost kot bralčevo literarno obzorje. 
Alejandro Rodríguez Díaz del Real

\section{The conquered conqueror Álvar Núñez Cabeza de Vaca and the conquered conqueror Sor Juana Inés de la Cruz. Analysis of two divergent identities from two brief works}

Keywords: Anti-Spanish Black Legend, Cabeza de Vaca, Sor Juana Inés de la Cruz, indigenism, Baroque

Starting from two recent critical publications against the fatalism of the traditional discourse of the (anti-Spanish) Black Legend, which do not pretend to be revisionist but instead point out certain positive aspects to the conquest of the Americas, the article contrasts two works that illustrate the permeability of two minds who wanted to open up to diversity: Álvar Núnez Cabeza de Vaca with his Shipwrecks (Naufragios) on the one hand, and Sor Juana Inés de la Cruz with his Allegorical Neptune (Neptuno alegórico) on the other. Only half a century after the discovery of America, and in the exact year of the New Laws of Charles V, which reflect the spirit of Las Casas critics and a defence of the Indian that later landed in the anti-Spanish Black Legend, Cabeza de Vaca presents a case of self-discovery as a fascinated conqueror who ends up conquered by the very environment that he is supposed to dominate; by a world that is too different and mysterious not to arouse his curiosity. The article contrasts this adventure of empathy and knowledge towards the other with an original work by Sor Juana Inés de la Cruz, Neptuno alegórico (1680), which represents another kind of journey, more a literary than autobiographical one, of the American world towards a Baroque or European "otherness". In spite of the considerable time that separates each case, and of the logical and predictable divergences in terms of literary genre, both works are united by a willingness to be carried away by cultural spheres and aesthetic guidelines that are far from the known world, doing what today we would call "leaving one's comfort zone", but achieving an enrichment of the authors' own lived and creative experience, as well as the literary horizon of the reader. 